\title{
PURULENT MENINGITIS OF UNUSUAL CAUSE
}

\author{
Major D. M. ROBERTS, \\ M.B., B.S., M.R.C.P.(Edin)., R.A.M.C. \\ Senior Medical Specialist \\ Major C. J. GARRETT, \\ M.B., Ch.B., M.R.C.P., D.T.M.\& H., R.A.M.C. \\ Senior Medical Specialist \\ British Military Hospital, Munster, B.A.O.R.
}

The death from acute illness of a previously healthy infant is always tragic and is often followed by self-recrimination on the part of the parents, and sometimes by those who have treated the child. Death can lurk unseen behind the apparently most trivial of daily occurrences. But how far is one justified in going, in order to preclude all possible harmful effects of such occurrences? We believe that the following case history illustrates this point and raises a question which, in the ultimate, is probably more philosophical than medical.

\section{Case History}

A 23 month old boy, who had had no previous illnesses, became febrile and developed vomiting which persisted for 24 hours, stopped for 12 hours and then started again. He drank plenty of fluid during the second day and urinary output remained fairly good. During the second night he became delirious, with a high-pitched cry, and lay curled up in bed with obvious photophobia, later becoming drowsy. He was first seen by a doctor at mid-day the next day, two days after onset, and was immediately admitted to hospital, having received no treatment.

Two days before the onset of this illness he had tripped and fallen whilst playing on gravel, receiving a very small cut below the right eyebrow. This episode was considered by his mother to be quite trivial and the cut had healed before admission to hospital. He had a pencil in his hand when he fell but this was inspected by his mother and found to be neither broken nor bloodstained.

On admission he was obviously very ill, lying curled up in bed, and the temperature was $102.8^{\circ} \mathrm{F}$, $\left(39.3^{\circ} \mathrm{C}\right.$.). He was comatose, responding only to painful stimuli, and there was marked photophobia. Gross neck stiffness and Kernig's sign were present. Muscle tone and tendon reflexes were increased in all four limbs, but plantar reflexes were both flexor. The fundi were normal and there were no localising signs in the nervous system. Dehydration was minimal. There was slight inflammation of the fauces, the earso were normal, and in the chest occasional scattered rhonchi were present. The cardiovascular system was normal apart from tachycardia, and so was the abdomen. The small laceration, one centimetre long, below the right eyebrow, appeared to have been quite superficial and had healed cleanly. A clinical diagnosis of purulent meningitis was made and investigations carried out accordingly.

Lumbar pucture yielded a purulent fluid at slightly increased pressure, containing 6,150 cells/c.mm., of which 90 per cent were polymorphonuclear and 10 per cent were lymphocytes, The fluid contained $480 \mathrm{mg}$. per cent protein, $6 \mathrm{mg}$. per cent sugar, 118 
$\mathrm{mEq}$ /L. chloride, and Pandy's test was strongly positive. No organisms were seen on stained smears and culture was sterile after 21 days. The meningococcal precipitation test was negative. Throat swab culture yielded a mixed growth of organisms, including beta-haemolytic streptococci. In the peripheral blood, haemoglobin was $9.8 \mathrm{G}$. per cent, (68 per cent), and the white cell count $24,400 / \mathrm{cmm}$., of which 90 per cent were polymorphonuclear, including 2 per cent myelocytes, with a marked shift to the left.

The aspirated cerebrospinal fluid was replaced by 10,000 units of intrathecal penicillin, and he was given intramuscular penicillin 500,000 units and intramuscular chloramphenicol $400 \mathrm{mg}$., both 6-hourly. He was given fluid and electrolytes by intragastric drip. Within $2 \frac{1}{2}$ hours of admission the depth of coma had lessened and, as he was becoming restless, $20 \mathrm{mg}$. phenobarbitone was given through the gastric tube. $2 \frac{1}{2}$ hours later he was twitching and convulsing, the right side being more involved than the left, and the legs more than the arms. He was therefore given a further $10 \mathrm{mg}$. phenobarbitone intramuscularly.

At 19.20 hours - 6 hours after admission-he suddenly became apnoeic and deeply cyanosed. Mouth to mouth respiration was given at once and when apnoea continued a cuffed tube was passed into the trachea and connected to a Radcliffe intermittent positive pressure respirator from which he respired 3 litres of air each minute. Later this was reduced to 2 litres per minute. He was also given intramuscular hydrocortisone $50 \mathrm{mg}$. During this time his pupils became fixed and dilated and he became increasingly cold. The rectal temperature at 21.00 hours was $93.0^{\circ} \mathrm{F}$., $\left(33.9^{\circ} \mathrm{C}\right.$.), and thereafter fell to $88.0^{\circ} \mathrm{F}$., $\left(31.1^{\circ} \mathrm{C}\right.$.).

Retention of urine necessitated catheterisation at 22.00 hours, when the urine was found to contain 2 per cent sugar. Blood sugar was therefore estimated and was 301 mg. per cent. At this time the serum electrolytes were: sodium $134 \mathrm{mEq}$. $/$ L., potassium $4.4 \mathrm{mEq}$. L., bicarbonate $15.8 \mathrm{mEq}$./L. and chloride $95 \mathrm{mEq} . / \mathrm{L}$. Repeat lumbar puncture, at which a further 5,000 units of intrathecal penicillin were introduced, revealed no significant change in the cerebrospinal fluid; it remained turbid with pus cells and contained protein $400 \mathrm{mg}$. per cent, sugar $46 \mathrm{mg}$. per cent and chloride $110 \mathrm{mEq} . \mathrm{L}$. Again, culture yielded no growth.

At this stage the fluid being given was changed to 1/6th. molar sodium lactate temporarily, and because of the need to correct the acidosis promptly, further fluid and electrolytes were administered through an intravenous cannula inserted at the ankle. There continued to be no sign of response to treatment. X-ray skull revealed no fracture or other abnormality and $x$-ray chest showed some patchy consolidation in the right upper lobe. Intramuscular sulphadimidine $2 / 3$ G. twice daily, with an initial double dose, was added to his treatment, intramuscular ampicillin $250 \mathrm{mg}$. 6-hourly was substituted for penicillin, and he was also given $10 \mathrm{mg}$. hydrocortisone intrathecally.

By 18.00 hours on the day after admission, (i.e. $28 \frac{1}{2}$ hours after admission), a definite general improvement began to occur, with the temperature gradually rising to $92.0^{\circ} \mathrm{F}$., $\left(33.3^{\circ} \mathrm{C}\right.$.). The limbs were again spastic with brisk tendon reflexes, and both plantar reflexes were now extensor. Spontaneous movements were now occuring, but there were still no localising signs. The skin remained blue, mottled and slightly oedematous, typical of hypothermia. Intravenous phenobarbitone $15 \mathrm{mg}$. 8-hourly and intravenous hydrocortisone $25 \mathrm{mg}$. 6-hourly were continued and he was given paired ampoules of Parenterovite into each litre of fluid. 
A Bird Mark 8 respirator was substituted for the Radcliffe at 20.30 hours in an attempt to eliminate the excess dead space which is a feature of the latter machine. However, despite the fact that he was "triggering" the respirator for short runs of up to 50 seconds at a time and his temperature had risen to $95.0^{\circ} \mathrm{F} .,\left(35.0^{\circ} \mathrm{C}\right.$.), spontaneous movements again ceased and by 23.30 hours complete generalised flaccidity had returned, the temperature again falling.

At 02.50 hours on the third day of admission-i.e. 37 hours after admissionimmediately after the longest spell of spontaneous breathing lasting for $2 \frac{1}{2}$ minutes, his heart stopped beating. In response to external cardiac massage and intraventricular injection of adrenaline the heart resumed beating after about five minutes asystole. Continuous electro-cardiographic monitoring was thereafter maintained; the record was surprisingly normal apart from some flattening of the $T$ wave most marked in lead V6. Cardiac arrest again occurred at 04.05 hours and three more times at 04.27 hours and each time the heart was restarted after about two minutes asystole. At this time serum electrolytes were : sodium $143 \mathrm{mEq} . / \mathrm{L}$., potassium $6.2^{*} \mathrm{mEq} . / \mathrm{L}$., chloride 90 mEq./L., bicarbonate $30.9 \mathrm{mEq}$./L. and the blood sugar was $366 \mathrm{mg}$. per cent. By this time the temperature had fallen to $87.0^{\circ} \mathrm{F}$., $\left(30.6^{\circ} \mathrm{C}\right.$.). Final cardiac arrest occured at 05.30 hours and he died $41 \frac{1}{2}$ hours after admission.

\section{Post-Mortem Findings}

Apart from some traumatic emphysema and pulmonary oedema, abnormal findings of significance were limited to the skull and brain and their integuments. There was a linear cleanly healed laceration, about a centimetre long, three quarters of a centimetre below the right eyebrow. From this a cleanly healing track led to a penetrating fracture of the right orbital plate. This fracture can best be described as a puncture wound such as might be made by a knitting needle point penetrating the skull by no more than 0.25 $\mathrm{cm}$. From this puncture site a hair-line fracture extended postero-medially for $1 \frac{1}{2} \mathrm{~cm}$.

The puncture itself was the only point at which the dura was breached. The dura was quite intact over the hair-line fracture, and it was obvious that no quantity of cerebrospinal fluid could have leaked from the puncture wound into the orbit, which was quite clean and free from extraneous matter.

The dura mater was tense and bulging and the meningeal vessels were congested. There was abundant greenish yellow exudate over the base of the brain, and over the vertex the exudate tended to follow the line of the blood vessels and was most marked over the frontal lobes and the anterior part of the parietal lobes. The ventricles were moderately dilated, and the choroid plexuses were hyperaemic.

No organism could be isolated from either the contents of the cerebrospinal space or the blood. It was of interest that the pathologist punctured his glove on a sharp spicule of bone during the post-mortem, and within 36 hours developed an infected finger with lymphangitis and lymphadenitis. This responded rapidly to cloxacillin.

\section{Discussion}

Speculation must inevitably centre around whether this boy's life could have been saved and, in any case, what lessons can be drawn from the case. For such speculation to be most profitable there is a need to be clear about the antecedent and ultimate causes of death, and this is not strictly possible. We do not, for example, know the identity of 
the organism responsible for the meningitis. That it was introduced through the orbital wound seems indisputable. The possibility of a leak of cerebrospinal fluid from the site of the skull injury, with secondary infection of the meninges, was considered but was excluded by the post-mortem findings. The purulent nature of the meningitis and the obvious virulence of the organism might suggest streptococci, staphylococci or Haemophilus influenzae. Beta-haemolytic streptococci, at least, were found to be present in the throat, but the resistance to treatment suggests either of the latter two organisms. Inability to culture the organism from the cerebrospinal fluid is usually due to administration of antibiotics prior to admission to hospital (Gossage, 1954), but it is by no means unknown in staphylococcal meningitis even before antibiotics have been administered, and we think that this was the most likely pathogen in this case. In retrospect, it does not seem that early blood culture would have yielded useful information.

It is interesting that a penetrating injury of the skull and meninges should have appeared so trivial, presumably solely on account of its small size. Apart from its apparent triviality, the important features of the injury were the latent period of 48 hours before the onset of symptoms, the fact that the wound appeared to heal quickly and cleanly-there being no foreign body implanted-and the fact that it gave rise to no $x$-ray changes. Apparent triviality and lack of $x$-ray changes in fatal penetrating injury of the skull were similarly noted in a case recently reported by Payne, (1966). Given knowledge of the existence of this traumatic intrusion into the cerebrospinal space, the question would arise as to whether excision and closure should have been attempted. It is axiomatic that when meningitis follows head injury the patient should be thoroughly investigated by a neurosurgeon (Lancet, 1966). A delay of four days between injury and admission to hospital, however, would weigh heavily against such immediate surgery and in this case the severity of his condition would have ruled it out. Is there, then, in general, a case for some sort of exploration of all injuries occurring about the skull, in which the skin is breached, no matter how trivial and regardless of whether or not systemic symptoms have developed? Obviously, some wounds will be overtly penetrating and should be explored. Simple probing may or may not be revealing, and it might be necessary to lay open the site of injury more thoroughly for inspection. Equally obviously, it would be quite impracticable to immediately explore every small cut or abrasion about the head. Ideally there should be a set of criteria by which to decide which wounds to explore and which to leave alone. Unfortunately, we believe that the present case demonstrates that any such rules would be fallible and could do no more than state the obvious. The same argument may be held to apply to the administration of prophylactic antibiotics for, say, five days after all such injuries. But here one begins to leave the realm of medicine and enter the realm of philosophy.

This case was treated as one of purulent meningitis, as indeed it was, but we were impressed and puzzled by what seemed to us to be an unusual feature- the way in which sudden relapse followed slight but definite general improvement. It was as if some intracerebral extension of the disease occured just when antibiotics were beginning to exert a beneficial effect against the infection. We wondered whether a cerebral abcess might account for this, the absence of localising signs by no means ruling this out. The possibility of a fractured skull was also seriously entertained, and x-rays were taken from several angles specifically to demonstrate the area of the right orbit; none of these was abnormal, In retrospect, there would probably have been justification for shaving the 
entire midline area of skin over the scalp in search for a congenital dermal sinus. Matson and Ingraham (1951) suggest that this should be done in all cases of unexplained meningitis. We were agreed that, at any rate, there must be some "built in" abnormal source of infection, and this belief proved fully justified.

There were, in fact, two catastrophic relapses following periods of slight general improvement, and each one was quite specific. One involved apnoea and the other asystole. Each would probably have proved immediately fatal had not a doctor been acutally present; (one of us was was actually listening to the heart when it stopped beating for the first time). The apnoea was probably due to involvement of the respiratory centre in the floor of the fourth ventricle by the inflammatory intumescence. The heat-regulating centre in the hypothalamus is not far away and the occurrence of striking hypothermia may also testify to more widespread involvement of the base of the brain.

It is less easy to explain the onset of asystole. Although the blood pressure was not detectable for much of the time, the heart rate before and after asystole was never higher than 110 per minute. This, to a certain extent, may have been due to hypothermia, in which the blood pressure is often low without compensatory tachycardia (Rosin and Exton-Smith, 1964; McNichol and Smith, 1964). Peripheral circulatory failure nevertheless seems likely to have been the ultimate cause of death. A local effect on the cardiac centre, which is both inhibitory and acceleratory, situated close to the middle of the nucleus ambiguus in the lateral area of the medulla cannot be ruled out. It is doubtful whether serum electrolyte imbalance contributed to cardiac arrest. Having been within normal limits, the serum potassium during the final crucial phase was $6.2 \mathrm{mEq} . / \mathrm{L}$., but this level is not usually considered to be of dangerous significance in infants of this age. There was certainly no electrocardiographic evidence of potassium excess. Acidosis was probably the result of tissue anoxia associated with hypothermia (Brewin et al, 1955). The correction of acidosis in hypothermia can normalise a profoundly abnormal electrocardiogram (Jones et al, 1966); however, in this case the acidosis had been corrected by the time the heart stopped.

It has long been known that severe acute cerebral disease can cause hyperglycaemia and glycosuria (Sachs and Macdonald, 1925; Munch-Peterson, 1931). One is tempted to speculate on the significance one might misguidedly place on the findings of heavy glycosuria and a blood sugar of over $300 \mathrm{mg}$. per cent in a comatose patient had he been seen for the first time at this stage and without the benefit of an adequate history.

Returning to the question of whether this life could have been saved, the answer is that it might possibly have been if the mother had sought help at a much earlier stage, and even then probably only if the significance of the blow below the right eyebrow had been appreciated.

\section{Summary}

The case is reported of a 23 month old boy who developed purulent meningitis and eventually died as a result of cardiac arrest following a long period of apnoea and hypothermia. Post-mortem revealed a small puncture wound penetrating the skull and meninges through the roof of the right orbit. This had resulted from a wound which was considered at the time to have been quite trivial and to have healed cleanly. It did not show on x-ray. The merit of early exploration of such wounds is discussed. 


\section{REFERENCES}

Jones, R. H. T., Bourdillon, R. E., Finn; R. and MARTIndale; K. (1966). Postgrad. med. J. $42,273$.

LANCET, (1966). $2,379$.

Brewin, E. G., Gould, R. P., Nashat, F. S. and NeIL, E. (1955). Guy's Hosp. Rep. 104, 177.

Gossage, J. D. (1964). Canad. Med. Ass. J. 90, 615.

Matson, D. J. and Ingraham, F. D. (1951). Paediatrics, Springfield. 8, 463.

MCNichol, M. W. and SMITH, R. (1964). Brit. med. J. 1, 19.

MunCh-PeTERson, C. J. (1931). Brain. 54, 72.

PAYNe, E. E. (1966). Brit. med. J. $2,807$.

Rosin, A. J. and EXTON-SMITH, A. N. (1964). Brit. med. J: 1, 16

SaChS, E. and MacDonald, M. E. (1925). Arch. Neurol. Phychiat. (Chicago): 13, 335.

\section{Our Colonel-in-Chief}

The following telegram was received by Lieutenant-General Sir Robert Drew, Director-General of Army Medical Services on the occasion of the R.A.M.C. Officers Annual Dinner, held on 21st April, 1967.

"I was deeply touched by the kind message of loyal greetings from the Colonels Commandant and Officers of the Royal Army Medical Corps assembled tonight at the United Services Club.

I send you all on the occasion of your annual dinner my warmest good wishes for a very enjoyable evening.

ELIZABETH R

Colonel-in-Chief."

\section{Medical Society of London}

Lieutenant-General Sir Robert Drew has recently been elected President of the Medical Society of London. This Society, one of the oldest in this country, was founded by Dr. John Coakley Lettsom, Quaker Physician, in 1773.

Dr. Lettsom was also responsible for founding the Royal Humane Society and the Royal Sea Bathing Hospital, Margate. A friend of Dr. William Jenner and Dr. John Fothergill, he campaigned strenuously for vaccination against smallpox, for prison reform, for improved living conditions of the poor and against Quacks and Charlatans. 